\title{
Heme oxygenase and indoleamine regulation by cytokines in cervical cancer cells and natural killer cells cytotoxic activity
}

\author{
Pablo C. Ortiz-Lazareno ${ }^{1}$, Paulina Gómez-Lomeli ${ }^{1}$, Georgina Hernández-Flores ${ }^{1}$, \\ Cristina Rodríguez-Padilla ${ }^{2}$, Francisco Javier Ochoa-Carrillo ${ }^{3}$ and Alejandro Bravo-Cuellar 1,4,*
}

${ }^{1}$ Immunology Division, Centro de Investigación Biomédica de Occidente, IMSS, Guadalajara, Jal.; ${ }^{2}$ Faculty of Biological Sciences, Universidad Autónoma de Nuevo León, San Nicolás de los Garza, N.L.; ${ }^{3}$ Surgical oncologist, Instituto Nacional de Cancerología de México, Ciudad de México; ${ }^{4}$ Department of Health Sciences, Centro Universitario de los Altos, Universidad de Guadalajara, Tepatitlán de Morelos, Jal. Mexico

\begin{abstract}
Objective: To determine the effect of the cytokines interleukin (IL-4), IL-10, Interferon gamma (IFN- $\gamma$ ) and tumor necrosis factor (TNF- $\alpha$ ) in protein expression of HO-1 and IDO in cervical cancer cell lines and the cytotoxicity of NK cells in co-culture with cervix cancer cells pretreated with HO-1 and IDO inhibitors. Methods: The cervical cancer cell lines HeLa (HPV 18+), SiHa (HPV 16+) and C-33A (HPV -) were treated with $20 \mathrm{ng} / \mathrm{mL}$ of IL-4, IL-10, IFN- $\gamma$ and TNF- $\alpha$ for $3 h, 6 h$ and $12 h$, after that protein expression was assessed by flow cytometry. The cytotoxic activity of NK cells was performed in real time for $4 \mathrm{~h}$. Results: Protein expression of the enzymes were changed at early times, increasing the expression of the enzymes in the 3 cell lines. We observed an increase in cytotoxic activity of NK cells cocultured with HeLa cells pretreated with the HO-1 inhibitor and in SiHa cells pretreated with the IDO inhibitor. Conclusion: The suppressor enzyme IDO is positively regulated by IL-10 in HeLa, SiHa, and NK cytotoxic activity increase in Hela and SiHa cells pretreated with HO-1 and IDO inhibitors respectively, which could be part of tumor escape mechanisms in cervix cancer.
\end{abstract}

Key words: Indoleamine. Histidine decarboxilase. Cervix cancer. Cytokines. NK cells.

Correspondence:

${ }^{\star}$ A. Bravo-Cuellar

E-mail: abravocster@gmail.com
Available online: 19-12-2017 Gac Mex Oncol. 2017;16(5):270-275

www.gamo-smeo.com 1665-9201 / @ 2017 Sociedad Mexicana de Oncología. Published by Permanyer México. This is an Open Access article under the terms of the CC BY-NC-ND license (http://creativecommons.org/licenses/by-nc-nd/4.0/). 


\section{Introduction}

Cervical cancer is the second most common cancer in women of developing countries ${ }^{1,2}$. The main risk factor for the development of this cancer is human papillomavirus (HPV) infection ${ }^{3,4}$. Although HPV infection does not induce an acute inflammatory response, an increased expression of cytokines such as TNF- $\alpha$ and IL-1 has been observed in patients with high and low grade lesions, as well as with cervical cancer $^{5}$.

A T-helper (TH1) response might be important in eliminating the virus, since it enhances cell response by means of the production of IL-2 and IFN- $\gamma$. Th2 response increases humoral immunity and, in consequence, IL-4 and IL-10 are released ${ }^{6}$. However, a Th2 response can produce an inadequate control of HPV infectious process, since IL-2 decreased expression and an increase in IL-4 have been found in high-grade lesions ${ }^{7}$, in addition to IL-10 overexpression in high-grade lesions when compared with low-grade lesions and normal cervical tissue ${ }^{8,9}$.

In HPV-associated lesions, both dendritic cells and myeloid stromal cells have been found to express the indoleamine (IDO) enzyme, which is known for its role in suppressor T-cell induction, which might contribute to the immunosuppression of immune system cells present in the tumor microenvironment, such as natural killer (NK) cells ${ }^{10}$, and facilitate tumor growth.

Indoleamine is the enzyme in charge to catabolize tryptophan, and it is encoded by a gene located in chromosome 8p12. In 1990, Munn DH, Mellor AL, et al. reported that IDO activity is essential in mice to prevent maternal allogeneic rejection of the fetus due to $\mathrm{T}$ ceII-mediated immunity. Subsequent studies have widely broadened IDO immunosuppressant role in a variety of chronic infections, including viral, parasitic and bacterial infections in the human being ${ }^{11,12}$.

IDO has been reported to be overexpressed in cervical cancer and cervical adenocarcinoma cells, whereas adjacent stromal cells lack such expression. In contrast, it is not expressed in cervical squamous epithelium or endocervical glands ${ }^{13}$.

Heme oxygenase-1 (HO-1) is the main enzyme implicated in heme group catabolism and gives rise to three fundamental products: biliverdin, free iron and carbon monoxide ${ }^{14}$. It plays an important role in the modulation of inflammatory processes and in the antioxidant defense mechanisms the body possesses when there is any damage present and in the blockage of apoptotic processes $^{15,16}$. This enzyme is overexpressed in pancreatic, colon and lung cancer, where it favors tumor proliferation and anti-tumor therapy resistance ${ }^{17,18}$. HO-1 induction in tumor cells subjected to any stressor agent increases its resistance to apoptosis. Furthermore, inhibition of this enzyme leads to tumor growth reduction and to an increase in sensitivity to chemotherapy ${ }^{19}$. In our laboratory we observed that, in NK cells co-cultured with cervical cancer cells previously treated with a HO-1 specific inhibitor, the production of IFN- $\gamma$ and TNF- $\alpha$ by NK cells was increased in comparison with those that were in contact with cell lines without treatment ${ }^{20}$.

However, the effect cytokines such as IL-4, IL-10, TNF- $\alpha$ and IFN- $\gamma$ may have on IDO and HO-1 expression in cervical cancer cell lines is not known, as neither is NK cells cytotoxic activity in cervical cancer cells previously treated with these inhibitors.

\section{Materials and methods}

\section{Cell culture}

The HeLa (HPV 18+), SiHa (HPV 16+), C-33A (HPV-) cell lines were donated by P. Boukamp (DKFZH Heidelberg, Germany), preserved in DMEM medium (Gibco, Life Technologies, Grand Island, New York, USA) supplemented with $10 \%$ of LPS-free fetal bovine serum (Gibco), $100 \mathrm{U}$ of penicillin and $100 \mu \mathrm{g}$ of streptomycin per each medium (Gibco) milliliter and 1\% L-glutamine (Gibco). To expand the NK-92 cells (ATCC no, CRL2407), RPMI 1640 (Gibco) culture medium, supplemented with $15 \%$ of LPS-free fetal bovine serum, was used, as well as $100 \mathrm{U}$ of penicillin and $100 \mu \mathrm{g}$ of streptomycin per each medium milliliter, 1\% L-glutamine and $80 \mathrm{U} / \mathrm{mL}$ of IL-2 (Biolegend, San Diego, CA, USA). All cell lines were incubated at $37^{\circ} \mathrm{C}$ in a humid atmosphere with $5 \% \mathrm{CO}_{2}$.

To determine IDO and HO-1 enzymes expression, the cervical cancer cell lines were seeded in $p-100$ plates $\left(1 \times 10^{6}\right.$ cells per plate), and were treated with TNF- $\alpha$, IFN- $\gamma$ (Biolegend), IL-10 or IL-4 (eBioscience, San Diego, CA, USA) at a $20 \mathrm{ng} / \mathrm{mL}$ concentration, in supplemented DMEM culture medium for 3,6 and $12 \mathrm{~h}$ at $37 \stackrel{\circ}{\circ}$ and with $5 \% \mathrm{CO}_{2}$.

The HeLa, SiHa and C-33A tumor cell lines were seeded in culture flasks and were separately treated with tin protoporphyrin IX (SnPP; Frontier Scientific, Inc. Logan, UT, USA), HO-1 inhibitor at a $25 \mu \mathrm{M}$ concentration and 1-L-methyltryptophan (1-MT; Sigma-Aldrich), IDO inhibitor, at a concentration of $2.5 \mathrm{mM}$, both for $48 \mathrm{~h}$. 


\section{Indoleamine and heme oxygenase 1 enzymes evaluation}

Once treatments with the cytokines were completed, the cancer cell lines were washed with PBS (Gibco) and fixed with fixative solution (Biolegend) for $20 \mathrm{~min}$. After a wash with permeating solution (Biolegend), permeability was induced with this solution for $5 \mathrm{~min}$. The cells were marked with the primary antibodies: mouse anti-human HO-1 (abcam, Cambridge, MA, USA) and mouse anti-human IDO-1 (AbD serotec, Oxford, United Kingdom) for $30 \mathrm{~min}$. Subsequently, the cells were incubated with the secondary antibodies: goat anti-mouse immunoglobulin G (IgG) coupled with fluorescein isothiocyanate (FITC; abcam) and rabbit anti-mouse IgG coupled with phycoerythrin (PE; AbD serotec), for $30 \mathrm{~min}$, protected from light. After incubation with the antibodies, the cells were washed with PBS, fixed with $0.5 \%$ paraformaldehyde (Sigma) in PBS and were analyzed in the flow cytometer EPICS-XL (Beckman Coulter Corp.). Data were analyzed using the WINMDI software, version 2.9. At least 20,000 events were acquired for each sample. Mean fluorescence intensity expression percentage and geometric mean of all experimental groups were obtained. Data were represented as the expression percentage mean.

\section{Cell death real-time evaluation}

Five-thousand tumor cells, pre-treated or not with HO-1 and IDO enzymes specific inhibitors, were seeded in a 96-well plate (E-plate; Roche), following the xCELLigence Real Time Cell Analyzer (RTCA; Roche) manual instructions; NK cells were added in sufficient amount to cover the target: effector range at 1:20, and the co-culture was maintained for $4 \mathrm{~h}$.

The normalized cell index $(\mathrm{nCl})$ was obtained with the RTCA software, and based on it, the percentage of lysis was calculated using the formula: lysis $\%=[\mathrm{nCl}$ (non-effector) $\mathrm{x} \mathrm{nCl}$ (effector)] $/ \mathrm{nCl}$ (non-effector) $\mathrm{x} 100$. The results are expressed as the average of at least three independent experiments performed in triplicate.

\section{Statistical analysis}

For statistical analysis, the means and standard deviation of at least three observations were obtained in triplicate for each one of the groups. Data were analyzed using the non-parametric Mann-Whitney U-test. Values with a $p$-value $\leq 0.05$ were considered to be significantly different.

\section{Results}

Interferon $\gamma$, TNF- $\alpha$, IL-4 and IL-10 reduce HO-1 expression in cervical cancer cell lines: to assess the effect of the treatment with cytokines on HO-1 expression, the HeLa, SiHa and C-33A lines were treated with $20 \mathrm{ng} / \mathrm{mL}$ of IL-4, IL-10, IFN- $\gamma$ and TNF- $\alpha$ for 3,6 and $12 \mathrm{~h}$. HO-1 expression in HeLa did significantly decrease $(p<0.05)$ since $3 \mathrm{~h}$ of treatment with IFN- $\gamma$ and TNF- $\alpha$, while IL-4 and IL-10 induced an expression decrease at $12 \mathrm{~h}$ of treatment (Fig. 1).

In $\mathrm{SiHa}$, only the treatment with IFN- $\gamma$ induced modifications in the expression of the enzyme, since it increased it 3 and $6 \mathrm{~h}(\mathrm{p}<0.05)$ after the cytokine was added. In C-33A, IFN- $\gamma$ increased HO-1 enzyme expression at $6 \mathrm{~h}$ of treatment, whereas TNF- $\alpha$ induced an increase in the enzyme expression at $3 \mathrm{~h}$, with this increase being maintained up to the $6 \mathrm{~h}$ time point in comparison with untreated cells.

IDO expression in cervical cancer cell lines is increased for short periods of treatment with the cytokines. Figure 2 shows the graphs of the IDO enzyme protein expression after treatment with the cytokines for 3,6 and $12 \mathrm{~h}$. IDO expression is increased in HeLa and $\mathrm{SiHa}$ at $3 \mathrm{~h}$, and in C-33A at $12 \mathrm{~h}$ of treatment with IL4. However, in general, there are no significant changes in the cervical cancer cell lines with regard to baseline levels observed in these cell lines. When SiHa and C-33A were treated with IL-10, IDO expression was significantly increased at $3 \mathrm{~h}$ of treatment $(p<0.05)$.

Treatment with IFN- $\gamma$ induces an increase in the expression of the enzyme in HeLa cells during the first $3 \mathrm{~h}(\mathrm{p}<0.05)$, and it decreases progressively over time until an expression similar to that of the baseline group is reached. In $\mathrm{SiHa}$, an IDO enzyme increase is observed from 6 and $12 \mathrm{~h}$ on $(\mathrm{p}<0.05)$. The cervical cancer cells were treated with TNF- $\alpha$, and an IDO expression increase is observed in $\mathrm{SiHa}$ and $\mathrm{C}-33 \mathrm{~A}$ at 3 and $12 \mathrm{~h}$ $(p<0.05)$.

Assessment of NK-mediated cytotoxicity in tumor cells treated with HO-1 (SnPP) and IDO (1-MT) inhibitors, in order to assess the participation of $\mathrm{HO}-1$ and IDO expressed by cervical cancer cell lines in the resistance to NK cells cytotoxic activity: the tumor cells were pretreated with specific inhibitors of these enzymes and co-culture with NK cells was subsequently carried out, with NK cell-mediated cell lysis being evaluated in real time. Figure 3 shows the percentage of NK cell-mediated lysis of the HeLa, SiHa and C-33A lines. HO-1 inhibition in the tumor cell lines favored an increase in the percentage of lysis, which was 
P.C. Ortiz-Lazareno, et al.: Heme oxygenase and indoleamine regulation by cytokines in cervical cancer cells

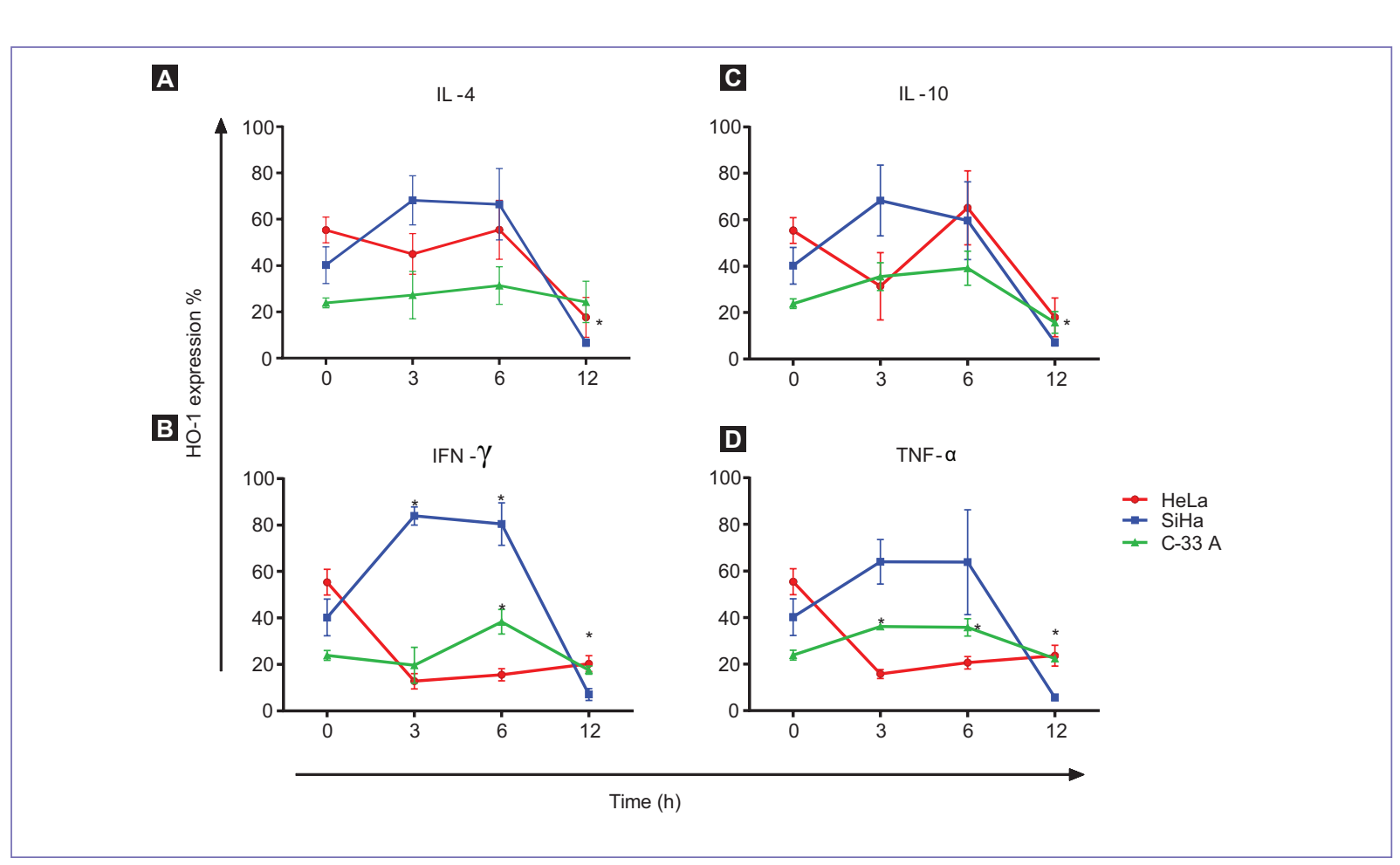

Figure 1. H0-1 expression kinetics. The HeLa, SiHa and C-33A cervical cancer cell lines were treated with: A) IL-4, B) IL-10, C) IFN- $\gamma$ and D) TNF- $\alpha$ for 3, 6 and $12 \mathrm{~h}$. The bars represent the standard error of the mean. Time 0 is regarded as the baseline expression $\left({ }^{*} p<0.05\right)$.

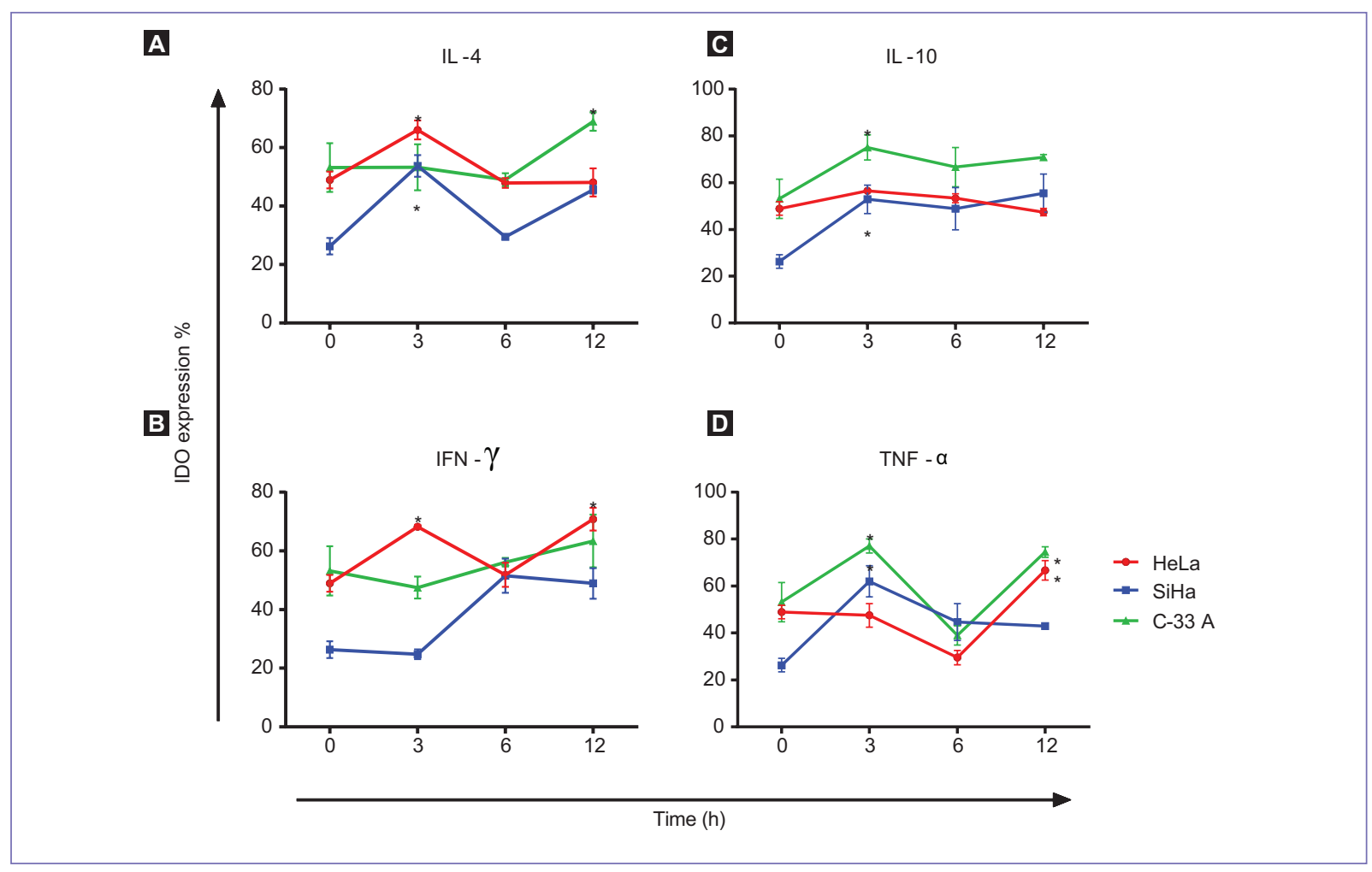

Figure 2. DOI enzyme expression kinetics. HeLa, SiHa and C-33A were treated for 3, 6 and $12 \mathrm{~h}$ with: A) IL-4, B) IL-10, C) IFN- $\gamma$ and D) TNF- $\alpha$. The bars represent the standard error of the mean. Time 0 is regarded as the baseline expression $\left({ }^{*} \mathrm{p}<0.05\right)$. 

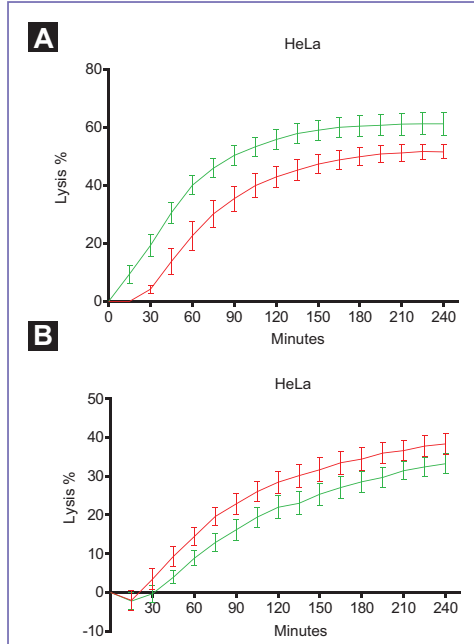

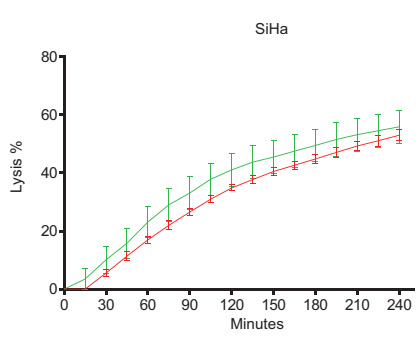

$\mathrm{SiHa}$

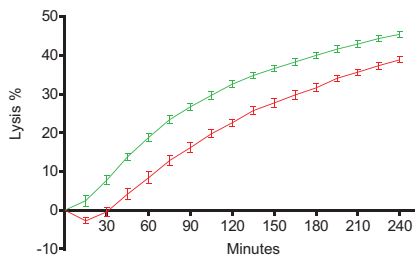

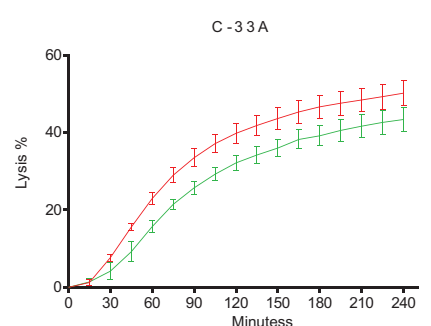

- $1: 20$ $-1: 20+$ SnPP 1:20+SnPP

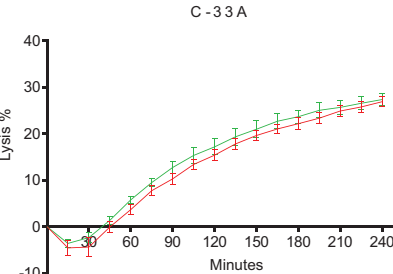

Figure 3. Cytotoxic activity of NK cells co-cultured with cervical cancer cells. HeLa, SiHa and C-33A cells were pretreated or not with: A) IDO inhibitor (1-MT) and B) H0-1 inhibitor (SnPP). NK cell-mediated cytotoxicity was determined in real time by measuring the impedance. The bars represent the standard error of the mean.

significant in HeLa (HPV 18+). On the other hand, IDO inhibition in the tumor cell lines favored an increase in the percentage of lysis in SiHa cells in comparison with cells not treated with the inhibitor (HPV 16+).

\section{Discussion}

Immune system cells and the release of their soluble mediators, such as cytokines, can shape tumor cells by favoring changes in order for them to produce molecules they normally would not express and that would enable them to evade apoptosis, proliferate without control and even evade the immune reponse ${ }^{21,22}$. The molecules tumor cells can express include certain cytokines (e.g., IL-10 and transforming growth factor beta [TGF- $\beta$ ]), chemokines such as CC chemokine receptor type 2 (CCR2) or enzymes such as IDO and HO-123,24.

$\mathrm{HO}-1$ and DOI overexpression has been reported in different types of cancer, including cervical can$\operatorname{cer}^{20,25,26}$. Regulation mechanisms of these enzymes range from transcription factors, which are activated by external stimuli, to products of enzyme activity ${ }^{27}$. IDO expression in response to cytokines is dependent on the cell type ${ }^{28}$, as it also is in the case of HO-1. For example, IFN- $\gamma$ has been reported to suppress $\mathrm{HO}-1$ expression in human glioblastoma cell lines, while TNF- $\alpha$ has no effect on the expression of this enzy$\mathrm{me}^{29}$. These variations were observed in our study, where, in spite of the three cervical cancer cell lines being epithelial cells, the response to the cytokines was different for each one of them.
In the HO-1 expression in the SiHa cell line, we may probably have observed a redundancy phenomenon between cytokines, since the enzymes' expression variation in time is the same for all four cytokines.

IFN- $\gamma$ induces an increase in IDO expression in the $\mathrm{HeLa}$ and $\mathrm{SiHa}$ cervical cancer cell lines during the first hours of treatment; in C-33A, the expression increases until $12 \mathrm{~h}$. In different types of cells, IFN- $\gamma$ is able to induce IDO expression ${ }^{30-32}$. In HLE-B3 epithelial cell lines, IDO enzyme activity increases proportionally to IFN- $\gamma$ concentration ${ }^{33}$.

Particularly in SiHa, TNF- $\alpha$ induces an IDO expression increase. With regard to TNF- $\alpha$, it has not been observed to have any effect on the expression of this enzyme ${ }^{32,34,35}$; however, it is able to potentiate its expression when combined with other pro-inflammatory cytokines ${ }^{30,32}$. In our study, we found that TNF- $\alpha$ induces expression changes, regardless of the cell type.

With regard to IL-10, this cytokine induces an increase in IDO expression during the first $12 \mathrm{~h}$ in the three cervical cancer cell lines, with this induction being lower in HeLa cells. In other studies, IL-10 has been reported to increase IDO enzyme expression in regulatory $\mathrm{T}$ cells $^{36,37}$.

Based in our observations, $\mathrm{HO}-1$ plays a protective role in HeLa (HPV 18+) cells, since when this enzyme is inhibited, NK cells cytotoxic activity is increased, while the IDO enzyme protects SiHa (HPV 16+) tumor cells from NK cells cytotoxicity. This is interesting, since it indicates there are different mechanisms to evade the immune response, particularly the response exerted by NK cells, as demonstrated in this study. These 
mechanisms are probably related to HPV infection and types, since in the HPV-negative C-33A line, these differences were not observed.

It should be highlighted that the changes observed in our study in the expression of the enzymes when challenged with cytokines occurred in short periods of treatment owing to the fact that these are stress-response enzymes, which confers a protecting role to the cells that express them ${ }^{28,38}$. Interestingly, this protecting role was confirmed when both HO-1 and IDO were inhibited, and the cells became more sensitive to NK cell-mediated cell death.

\section{Conclusions}

The HO-1 enzyme expression decreases when tumor cells are treated with different cytokines, and other cytokines or molecules may therefore be involved in its regulation. The suppressive enzyme IDO is positively regulated by IL-10 in HeLa and SiHa, and thus it could be part of tumors' evasion mechanisms in cervical cancer. NK cells cytotoxic activity is increased in HO-1 inhibitor-pretreated HeLa cells and in IDO inhibitor-pretreated SiHa cells.

\section{Acknowledgements}

To the Fondo de Investigación en Salud, for the FIS/ IMSS/PROT/508 funding granted for the performance of this work, and to Red Temática del CONACYT de Inmunología en Cáncer y Enfermedades Infecciosas INMUNOCANEI-CONACYT No. 280135.

\section{Conflict of interests}

The authors declare not having any conflicts of interests.

\section{References}

1. Jemal A, Bray F, Center MM, et al. Global cancer statistics. CA Cancer $J$ Clin. 2011;61(2):69-90.

2. Torre LA, Bray F, Siegel RL, Ferlay J, Lortet-Tieulent J, Jemal A. Global cancer statistics, 2012. CA Cancer J Clin. 2015;65(2)87-108.

3. Jayshree RS, Sreenivas A, Tessy M, Krishna S. Cell intrinsic \& extrinsic factors in cervical carcinogenesis. Indian J Med Res. 2009;130(3):286-95.

4. Schiffman M, Castle PE, Jeronimo J, Rodríguez AC, Wacholder S. Human papillomavirus and cervical cancer. Lancet. 2007;370:890-907.

5. Jabbour HN, Sales KJ, Catalano RD, Norman JE. Inflammatory pathways in female reproductive health and disease. Reproduction. 2009; 138: 903-19.

6. Mosmann TR, Cherwinski H, Bond M, Giedlin M, Coffman R. Two types of murine helper T cell clone. I. Definition according to profiles of lymphokine activities and secreted proteins. J Immunol. 1986;136(7):2348-57.

7. Al-Saleh W, Giannini SL, Jacobs N, et al. Correlation of T-helper secretory differentiation and types of antigen-presenting cells in squamous intraepithelial lesions of the uterine cervix. J Pathol. 1998;184(3):283-90.

8. Giannini SL, Al-Saleh W, Piron H, et al. Cytokine expression in squamous intraepithelial lesions of the uterine cervix: implications for the generation of local immunosuppression. Clin Exp Immunol. 1998;113(2):183-9.

9. Peghini BC, Abdalla DR, Barcelos AC, Teodoro Ld, Murta EF, Michelin MA. Local cytokine profiles of patients with cervical intraepithelial and invasive neoplasia. Human Immunol. 2012;73(9):920-6.
10. Kobayashi A, Weinberg V, Darragh T, Smith-McCune K. Evolving immunosuppressive microenvironment during human cervical carcinogenesis. Mucosal Immunol. 2008;1(5):412-20.

11. Katz JB, Muller AJ, Prendergast GC. Indoleamine 2,3-dioxygenase in T-ceII tolerance and tumoral immune escape. Immunol Rev. 2008;222:206-21.

12. Liu X, Newton R, Friedman S, Scherle P. Indoleamine 2,3-dioxygenase, an emerging target for anti-cancer therapy. Curr Cancer Drug Targets. 2009:9(8):938-52

13. Inaba $\mathrm{T}$, Ino K, Kajiyama $\mathrm{H}$, et al. Indoleamine 2, 3-dioxygenase expression predicts impaired survival of invasive cervical cancer patients treated with radical hysterectomy. Gynecol Oncol. 2010;117(3):423-8.

14. Chabannes D, Hill M, Merieau E, et al. Arole for heme oxygenase-1 in the immunosuppressive effect of adult rat and human mesenchymal stem cells. Blood. 2007;110(10):3691-4.

15. Piantadosi CA, Withers CM, Bartz RR, et al. Heme oxygenase-1 couples activation of mitochondrial biogenesis to anti-inflammatory cytokine expression. J Biol Chem. 2011;286(18):16374-85.

16. Ryter SW, Alam J, Choi AMK. Heme Oxygenase-1/Carbon Monoxide: From Basic Science to Therapeutic Applications. Physiol Rev. 2006;86(2):583-650.

17. Berberat PO, Dambrauskas Z, Gulbinas A, et al. Inhibition of Heme Oxygenase- 1 Increases Responsiveness of Pancreatic Cancer Cells to Anticancer Treatment. Clin Cancer Res. 2005;11(10):3790-8.

18. Castronuovo CC, Sacca PA, Meiss R, et al. Homeostatic response under carcinogen withdrawal, heme oxygenase 1 expression and cell cycle association. BMC Cancer. 2006;6:286.

19. Simon T, Anegon I, Blancou P. Heme oxygenase and carbon monoxide as an immunotherapeutic approach in transplantation and cancer. Immunotherapy. 2011;3:15-8.

20. Gómez-Lomelí $P$, Bravo-Cuellar A, Hernández-Flores $G$, et al. Increase of IFN- $\gamma$ and TNF- $\alpha$ production in CD107a+ NK-92 cells co-cultured with cervical cancer cell lines pre-treated with the HO-1 inhibitor. Cancer $\mathrm{C}$ Int. 2014;14(1):100.

21. Bhatia A, Kumar Y. Cancer Immunoediting: Immunosurveillance, Immune Equilibrium, and Immune Escape, In: Rezaei N. (eds) Cancer Immunology. Springer, Berlin, Heidelberg. 2015;195-208.

22. Hanahan D, Weinberg RA. Hallmarks of cancer: the next generation. Cell. 2011;144(5):646-74.

23. Cavallo F, De Giovanni C, Nanni P, Forni G, Lollini PL. 2011: the immune hallmarks of cancer. Cancer Immunol Immunother. 2011; 60(3):319-26.

24. Zitvogel L, Tesniere A, Kroemer G. Cancer despite immunosurveillance: immunoselection and immunosubversion. Nature Rev Immunol. 2006;6:715-27.

25. Takikawa $O$. Clinical aspects of indoleamine 2,3-dioxygenase (IDO)-initiated tryptophan metabolism: IDO is a target of drug discovery for various diseases. International Congress Series. 2007;1304:290-7.

26. Was H, Dulak J, Jozkowicz A. Heme oxygenase-1 in tumor biology and therapy. Current Drug Targets. 2010;11:1551-70.

27. Kim KM, Pae HO, Zheng M, et al. Carbon monoxide induces heme oxygenase-1 via activation of protein kinase R-like endoplasmic reticulum kinase and inhibits endothelial cell apoptosis triggered by endoplasmic reticulum stress. Circ Res. 2007;101(9):919-27.

28. Mellor AL, Munn DH. IDO expression by dendritic cells: tolerance and tryptophan catabolism. Nature Rev Immunol. 2004;4:762-74.

29. Takahashi K, Nakayama M, Takeda K, Fujia H, Shibahara S. Suppression of heme oxygenase-1 mRNA expression by interferon-gamma in human glioblastoma cells. J Neurochem. 1999;72(6):2356-61.

30. Babcock TA, Carlin JM. Transcriptional activation of indoleamine dioxygenase by interleukin 1 and tumor necrosis factor $\alpha$ in interferon-treated epithelial cells. Cytokine. 2000;12(6):588-94.

31. Munn DH, Mellor AL. Indoleamine 2, 3-dioxygenase and tumor-induced tolerance. J Clin Investigation. 2007;117:1147-54.

32. Robinson CM, Hale PT, Carlin JM. NF-KB activation contributes to indoleamine dioxygenase transcriptional synergy induced by IFN- $\square$ and tumor necrosis factor- $\alpha$. Cytokine. 2006;35(1):53-61.

33. Mailankot M, Nagaraj $\mathrm{RH}$. Induction of indoleamine 2, 3-dioxygenase by interferon-gamma in human lens epithelial cells: apoptosis through the formation of 3-hydroxykynurenine. Int J Biochem Cell Biol. 2010;42(9):1446-54.

34. Braun D, Longman RS, Albert ML. A two-step induction of indoleamine 2, 3 dioxygenase (IDO) activity during dendritic-cell maturation. Blood. 2005;106(7):2375-81.

35. Däubener W, Mackenzie CR. IFN activated indoleamine 2,3- dioxygenase activity in human cells is an antiparasitic and an antibacterial effector mechanism. Adv Exp Med Biol. 1999;467:517-24.

36. Battaglia M, Gianfrani C, Gregori S, Roncaroloa MG. IL-10区 Producing T Regulatory Type 1 Cells and Oral Tolerance. Ann N Y Acad Sci. 2004;1029:142-53

37. Mocellin S, Marincola FM, Young HA. Interleukin-10 and the immune response against cancer: a counterpoint. J Leukoc Biol. 2005; 78(5):1043-51.

38. Keyse SM, Tyrrell RM. Heme oxygenase is the major $32-\mathrm{kDa}$ stress protein induced in human skin fibroblasts by UVA radiation, hydrogen peroxide, and sodium arsenite. Proc Natl Acad Sci U S A. 1989; 86(1):99-103. 